\title{
The first steps for learning optics: Ibn Sahl's, Al-Haytham's and Young's works on refraction as typical examples
}

Mourad Zghal, Hamid-Eddine Bouali, Zohra Ben Lakhdar, Habib Hamam

Mourad Zghal, Hamid-Eddine Bouali, Zohra Ben Lakhdar, Habib Hamam, "The first steps for learning optics: Ibn Sahl's, Al-Haytham's and Young's works on refraction as typical examples," Proc. SPIE 9665, Tenth International Topical Meeting on Education and Training in Optics and Photonics, 966509 (3 June 2007); doi: 10.1117/12.2207465

SPIE Event: Tenth International Topical Meeting on Education and Training in Optics and Photonics, 2007, Ottawa, Ontario, Canada 


\title{
The first steps for learning optics: Ibn Sahl's, Al- Haytham's and Young's works on refraction as typical examples
}

\author{
Mourad Zghal ${ }^{1,2}$, Hamid-Eddine Bouali ${ }^{2}$, Zohra Ben Lakhdar ${ }^{2}$ and Habib Hamam ${ }^{3}$ \\ ${ }^{1}$ Engineering School of Communications of Tunis (Sup'Com), University of 7 November at Carthage \\ Cité Technologique des Communications, 2083 Ariana, Tunisia \\ Phone: +216 71857 000; Fax: +21671856 829; mourad.zghal@supcom.rnu.tn \\ ${ }^{2}$ Optical Society of Tunisia, Physics Department, Faculty of Sciences of Tunis, Tunis 1060,Tunisia; zohra.lakhdar@fst.rnu.tn \\ ${ }^{3}$ Department of Engineering, Université de Moncton, NB, Canada; habib.hamam@umoncton.ca
}

\begin{abstract}
Optics scholars did not only discover optical phenomena and laws governing them. Some of them also invented impressive optical systems and instruments or offered us techniques to juggle with optical signals and rays. One typical example of the impressive optical systems is the camera obscura invented by Ibn AlHaytham. For techniques enabling us to easily handle optical rays, one can mention Young's method to handle rays put into play by refraction. Nine centuries before him, Ibn Sahl proposed an elegant method to manipulate refraction related rays. These three examples will be handled in this paper, together with a historical overview inviting the reader to be in the context of this fascinating works.
\end{abstract}

\section{Introduction}

We cannot be grateful enough to optics scientists, during the running wheel of history, who enabled us to rapidly understand optics and to tackle specific research tasks in optics or to design particular optical components or systems. They did discover a huge number of optical phenomena. They elaborated and formulated the laws associated to these phenomena in such a way we can use them. Some of them also invented impressive optical systems and instruments or offered us techniques to easily handle optical signals and rays. In this paper we will focus on three findings of those scholars, which are strongly related to learning optics. We will treat Ibn Al-Haytham's camera obscura. For techniques enabling us to easily handle optical rays, we will take the case of Young's method to handle rays put into play by refraction. This famous scholar was preceded, nine centuries before, by Ibn Sahl who proposed another elegant technique to manipulated refraction related rays. These three examples will be handled in this paper, together with a historical overview inviting the reader to be in the context of this fascinating works. The remainder of this paper is organized as follows. Section 2 presents a historical review of achievements in Optics. In this review, we will focus on Al-Haytham's contributions as well as previous and subsequent works to emphasize the continuity of achievements through the link between scientific observations, interpretations and criticisms during the turning wheel of history. While section 3 briefly addresses the medieval Islamic achievement in optics, section 4 focuses on Al-Haytham's contributions from which optics scientists profited widely and for a long time and are still profiting. In relation with learning optics, we take the camera obscura as an example. This fascinating experiment is in our opinion one of the most exciting and motivating examples to teach optics and to make it readily understandable by laypeople. Results are presented in section 5. Finally, section 6 presents some concluding remarks.

\section{Brief historical overview of achievements in optics}

Historically, light was a center of interest for numerous inquisitive people: the philosophers who were interested in its nature and the scientists who wanted to interpret its associated phenomena. In antiquity, the Egyptians attempted to discover the mystery of light and to know its structure [1]. From a philosophical point of view, their attempts were fruitless. However in practice, they implemented impressive mechanisms mainly based on reflection. The Greeks also attempted to decode the enigma of light and considered it a continuous phenomenon propagating in the form of a substance current called the "visual ray". Nevertheless, based on the work of the Egyptians, they established rules for light deflection [2]. One of the most impressive legacies of the Greeks in optics is the mirror of Archimedes. Aristotle [3], interested in the sensation in general, refused to admit the existence of the visual ray and believed in the analogy between light and sound whose vibratory nature was already known [4]. In the $\mathrm{XI}^{\text {th }}$ century, the thesis of the visual ray was definitively abandoned by the Iraqi Ibn Al-Haytham [5] whose work revolutionized the optics [6,7]. He detached Optics from its philosophical envelope and embedded it in the framework of physics and mathematical sciences [5]. He dealt at length with the theory of various physical phenomena like shadows, eclipses, the rainbow, and speculated on the physical nature of

Tenth International Topical Meeting on Education and Training in Optics and Photonics, edited by Marc Nantel, Proc. of SPIE Vol. 9665, 966509 • (c) 2007 SPIE, OSA, IEEE, ICO doi: $10.1117 / 12.2207465$ 
light. Al-haytham's optics entered Spain in the XII ${ }^{\text {th }}$ century and was adopted by Grossteste [8], who affirmed the analogy between light and sound $[9,10]$ and thoroughly investigated the matter of geometrical optics.

After the contributions of the geometro-opticians, Snell and Descartes [11] studied the refraction phenomenon and stated that the speed of light is as high as the covered medium is dense. This hypothesis was contested by Fermat [12], who attributed indices to the media. Foucault in the XIX ${ }^{\text {th }}$ century came out in favour of Fermat. This more modern progress still dealt only with geometrical optics which considered that the behavior of light with respect to obstacles is expressed uniquely in terms of absorption, reflection or refraction. However, in the $\mathrm{XVII}^{\text {th }}$ century, Grimaldi, using a simple experiment, had observed the progressive transition between light and shadow and regarded the corpuscular theory, supposing the rectilinear propagation of light, as insufficient to explain such an effect [13]. Despite Newton's support of the corpuscular theory [14] (He believed that the light propagation is a movement of corpuscles that respects the rules of mechanics and notably that of the universal gravitation), Huygens advanced the ondulatory theory based on Grimaldi's observations. He explained Grimaldi's observation by a purely intuitive postulation, in which he regarded light propagation as an incessant creation of elementary spherical light sources [15].

At the beginning of the XIX ${ }^{\text {th }}$ century, after some experiments on the colors of thin plates, T. Young came to the conclusion that the interaction between light rays may produce darkness, thereby discovering a wonderful phenomenon which he called "interference" [16]. Like Huygens, Young supported the ondulatory theory. He also developed an elegant technique to handle refraction (it will be treated in the experimental part). His belief in the analogy between light and sound leads him to state that light vibration is longitudinal [17]. The famous A. Fresnel was of the same opinion. However he considered that Huygens' postulation did not explain the nonexistence of waves that have the same specifications propagating backwards. He combined Huygens' principle of the "envelope" building, with the interference principle of Young and, for the purpose of putting forward a coherent theory, he made some supplementary hypotheses on the amplitude and phase of the new elementary waves. At the end of the XIX ${ }^{\text {th }}$ century, G. Kirchhoff gave a deeper mathematical basis to the diffraction theory introduced by Huygens and Fresnel, and considered Fresnel's hypothesis as a logical consequence of the ondulatory nature of light. Kirchhoff's work was subjected a few years later to criticisms made by Sommerfeld who considered the Kirchhoff formulation as a first approximation. He advanced with Rayleigh what was later called the "Rayleigh-Sommerfeld diffraction theory". Hence, a supplementary phenomenon called "diffraction" is added to those concerning the behavior of light when coming across obstacles, namely absorption, reflection, refraction, diffusion and dispersion. Sommerfeld defined this phenomenon conveniently as follows [18]: "Diffraction is any deviation of light rays from the initial path which can be explained neither by reflection nor by refraction".

Because medieval Islamic contributions in optics are not commonly known by optics community, we will devote a separate section for this era.

\section{Medieval Islamic contributions in optics}

As stated by Lindberg [19], the Islamic contribution to the science of optics within the medieval Islamic world should be measured not by the number of practitioners, which was small, but by the quality of the contributions, which was great. Let us briefly recall some scientific contributions in optics and limit attention to six scientists in chronological order. A separate section will be devoted to the famous scientist Ibn Al-Haytham.

\section{1. Al-Kindi}

Yaqub Ibn Ishaq Ibn Sabah Al-Kindi (c. 801-873), popularly known as the "Philosopher of the Arabs" in the Middle Ages, was one of the earliest important optics scientists in the Islamic world. His theory of the active power of rays, stating that any luminous object emits rays in every direction, influenced several European scientists like Grosseteste, Bacon and Watelo [20,21]. In other words, he pointed out the incoherent behavior of light and therefore challenged the ancient assumption that light emanates from luminous objects as a single, holistic unit [19]. Al-Kindi's observations and interpretations influenced the course of thinking for centuries. Moreover, he defended Euclid's theory of visual power issuing forth from the eye and suggested some corrections. It was necessary to wait for Al-Haytham's revolutionary theory, two centuries later, to abandon the assumption of radiation moving out of the eye in favour of the statement that light moves in. 


\section{2. Ibn Ishaq}

The trilingual Nestorian Christian, Hunayn Ibn Ishaq (Isac), contemporary and neighbour to Al-Kindi in Baghdad, was one of the most illustrating examples of the peaceful and fruitful multi-cultural and multireligious cohabitation in Baghdad. He wrote ten Treatises on the Eye and claimed that the sensitive organ of the eye is the crystalline lens, located in the center of the eye. He was a leading administrator of the translating enterprise and translated several works from Greek to Arabic with Syriac as a probable intermediate step. He supervised Jewish, Christian and Muslim translators [22].

\section{3. Ibn Sahl}

In the same place, Baghdad, but in the next century $\left(10^{\text {th }}\right)$, another scientist, called Abu Sad Al Alla Ibn Sahl, excelled in Optics. Author of a treatise on Burning Mirrors and Lenses, he was an optics engineer associated with the court of Baghdad. He wrote his textbook in 984 where he set out his understanding of how curved mirrors and lenses bend and focus light (see Figure 1). R. Rashed credited Ibn Sahl with discovering the law of refraction [23], usually called Snell's law and also Snell and Descartes' law. It worth noting that Snell's law, discovered in 1621 in Holland, was not well known until Descartes (1596-1650) published it in 1638. Even then he did not make it clear that he was following Snell, so for some time Descartes was regarded as the originator of Snell's law. Similarly, Ibn Al-Haytham is the inventor of the pinhole camera, but the idea was later credited by Della Porta for redescribing how the camera works.

We recall this law: $n \sin (i)=n^{\prime} \sin \left(i^{\prime}\right)$, where $n$ and $n^{\prime}$ are the refraction indices in the first and second medium and $i$ and $i$ ' are respectively the incidence and refraction angles. For small values of $i$ (expressed in radian and not in degree), the law can be approximated as follows: $n i=n^{\prime} i$ '

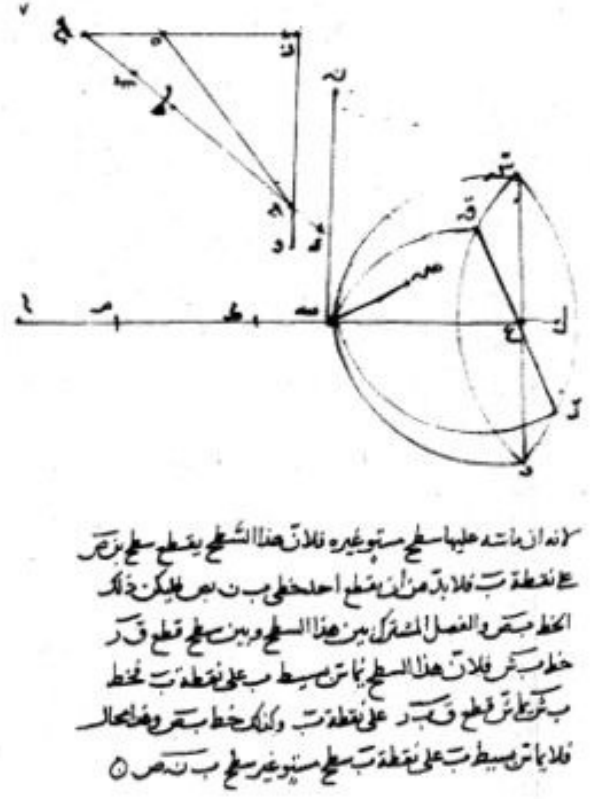

Figure 1: Reproduction of a page of Ibn Sahl's manuscript showing his discovery of the law of refraction [23].

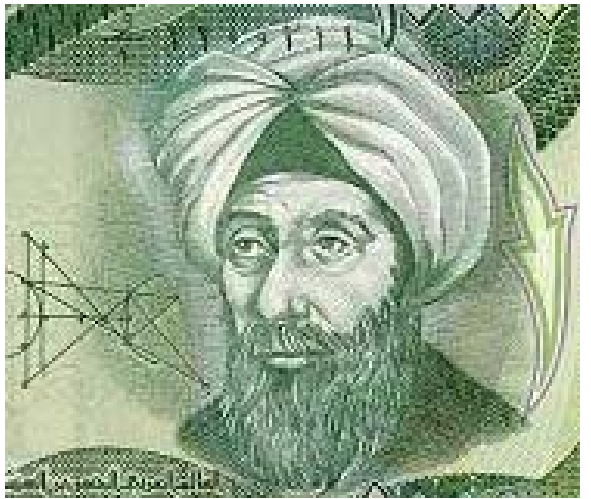

Figure 2: Ibn Al-Haytham's symbolic photo in an Iraqi 10,000-dinar note.

By examining Figure 1, Rashed's thesis looks very defendable. Let us have a close look at the top-left part of the Figure, where we see two right angles. The inner hypotenuse stands the path of an incident ray. Let us say that its length is $h$ and the incidence angle with respect to the horizontal line is $i$. The outer hypotenuse, with length $h^{\prime}$ and angle $i$ ', shows an extension of the path of the refracted ray. Here, the incident ray meets a crystal whose face is vertical at the point where the two hypotenuses intersect [24]. According to R. Rashed [23], the ratio of the length of the smaller hypotenuse to the larger is the reciprocal of the refractive index of the crystal. In mathematical terms, $h / h^{\prime}=1 / n^{\prime}$ or $h / h^{\prime}=n / n^{\prime}$ with $\left(\mathrm{n}=1\right.$ the refraction index of the air). Because $h / h^{\prime}=$ $\sin \left(i^{\prime}\right) / \sin (i)=n / n$ ', we find the law of refraction mentioned above. Ibn Sahl's treatise was used later by Ibn AlHaytham. R. Rashed reassembled the manuscript parts, dispersed over two libraries, and translated it into French [25]. 


\section{4. Al-Quhi}

In the same century $\left(10^{\text {th }}\right)$ and in addition to geometrical mathematics, the Persian, Abu Sahl Waijan Ibn Rustam Al-Quhi, also known as Abu Sahl Al-Kuhi or just Kuhi, studied optics and investigated the optical properties of mirrors made from conic sections. His renown came also from his skills in the manufacturing of optical observation instruments [26].

\section{5. Ibn Al-Haytham}

Because a special section is devoted to Ibn-Alhaythm, let us just mention two of his followers.

3. 6. Al-Shirazi

Qutb Al-Din Al-Shirazi (1236-1311) continued the optical studies of Ibn Al-Haytham. Georges Sarton considers Al-Shirazi to be one of the prominent scientists in mathematics, astronomy, optics and philosophy [21]. His main contributions in physics was his "unprecedented comprehensive explanation of the rainbow, as he demonstrated that the rainbow phenomenon occurs when sun rays fall on the small water drops that prevail in the air when it's raining. The sun rays then undergo an internal reflection and become apparent to the eye" [27]. He was the first scientist giving a correct explanation for the formation of the rainbow.

3. 7. Al-Farisi

Kamal Al-Din Al-Farisi (1260-1320). He was concerned by light, colour and the rainbow [28]. His work was discussed in the Dictionary of Scientific Biography [29]. Al-Farisi was a pupil of Al-Shirazi. His work on optics was prompted by a question put to him concerning the refraction of light. Al-Shirazi advised him to consult the Ibn Al-Haytham's work. Al-Farisi made such a deep study of this treatise. The professor, Al-Shirazi, suggested to his student, Al-Farisi, to write what is essentially an amendment of Al-Haytham's major work, which came to be called in Arabic the "Tanqih".

\section{Ibn Al-Haythm's attempts and achievements}

Abu Ali Hasan Ibn Al-Haitham (c.965-1039), known by Europeans as "Alhazen" (Al Hasan), was born in Basra, where he received his education. Sir Thomas Arnold considers that "the field of optics reached its peak with Ibn Al-Haytham" [30]. Sarton says "Ibn Al-Haitham was the best scientist to have existed in the Islamic world in the middle ages in the field of natural science. He was one of the few most outstanding figures in optics in all times. He was also an astronomer, a mathematician and a doctor" [21]. The Encyclopaedia Britannica considered him as the leading figure in optics after Ptolemy [27].

\subsection{Scientific experimental method}

Ibn Al-Haytham is one of the very early founders of the scientific method. Ibn Al-Haytham rejected Aristotle's theory (384-322 B.C.) claiming that there is a difference between the laws governing events on earth and those pertaining to celestial bodies. He considered that light is traveling with respect to well defined physical laws, regardless of its source and where this source is. In this sense, he anticipated the universal laws of seventeenth century scientists. Light coming from the sun, reflected by the moon, emitted by fire, reflected by a mirror or focussed by a lens, is light and it undergoes the same effects and phenomena. Light, used in the camera obscura setup, is identical to light causing the rainbow effect. In other words, light is universal. If one allows oneself to do the parallel to the universal gravitation, Ibn Al-Haytham, mainly concerned by optics, anticipated the universal laws of seventeenth century scientists. He opted for an experimental approach (optical observations) to prove his scientific interpretation. For example, he implemented, the camera obscura to experimentally prove that rays travel in straight lines and that the image is reverted like the retinal image. He also concluded from his various experiments that light weakens as it travels from its source. His writings clearly point out a scientific method including the systematic observation of physical phenomena and their linking together into a scientific theory. Ibn Al-Haytham's influence on physical sciences in general and optics in particular, has been held in high esteem at the level of both theory and practice.

\subsection{Human eye}

Where do the names of the optical components of the eye come from? They are indeed Ibn-Haytham's appellations: cornea (القرنية), retina (الثبكية), Vitreous Humor (السائل الزجاجي), Aqueous Humor (النبائل المائي), etc. [31]. Ibn Al-Haytham is the founder of the Psychology of Vision. In his anatomy, he was able to identify the eye layers with great precision and to define his lens system as comprising of the aqueous and vitreous humors and the lens. In addition, he identified the neural components of the visual system including the retina, the optic path and the optic chiasma (part of the brain where the optic nerves partially cross). His Psychophysics was based on a clear understanding of the optic mechanisms of the convex and concave layers of the eye, the visual angle and 
the reversal of the visual image. He provided explanation of the visual constancy's, perception of distance, form and orientation. His explanation cannot be distinguished from the one retained in the psychology of vision today. Al-Haytham work in optics in general and in vision in particular hugely influenced western scientistssuch as Bacon, Witelo, Pechan and ultimately Kepler who provided an improvement of the understanding of the eye five centuries later.

\subsection{The first spectacles}

Ibn Al-Haytham is one of the scholars often credited with inventing spectacles [32], although that credit is more commonly given to Roger Bacon. It is well known that Ibn-Haytham proved the magnification ability of convex lenses. Islamic history revealed that when he became old, he designed a convex lens to continue reading scientific treatises. He realized that each eye requires a specific correction (binocular vision) and used two convex lenses with different powers.

\subsection{Light dispersion}

He also carried out the first experiments on the dispersion of light into its constituent colours. Indeed, the rainbow incited the Ibn Al-Haytham's curiosity. By exposing water-filled glass globes to sunlight, he discovered that rainbows are caused by refraction not by sunlight reflecting off raindrops, as Aristotle had claimed. Ibn AlHaytham mage the first experiment in history showing how to disperse light, to break white light into its constituent colors. He made a close look at sunlight passing through his water-filled globes; he could see the beams of light refracted at measurable angles. He realized that each band in the resulting multi-colored beam had been refracted at a different angle, and that each color always occurred at the same angle. Ibn Al-Haytham demonstrated that the prism made the colors visible by refracting rays of different colors in varying amounts, thus producing the familiar spectrum.

\subsection{Sun and the atmosphere}

Ibn Al-Haytham gave a correct explanation of the apparent increase in size of the sun and the moon when near the horizon. Ibn Al-Haytham has discussed the density of the atmosphere and related it to altitude. He also studied atmospheric refraction. He discovered that the twilight only ceases or begins when the Sun is $19^{\circ}$ below the horizon and attempted to measure the height of the atmosphere on that basis. For Ibn Al-Haytham and his contemporary scientists, the fact that the earth is spherical is not debatable. Their experiments do not leave the slightest doubt about the spherical shape of the earth. We believe that this kind of knowledge belongs to laypeople at that time. Cartographers and geographers, like Ahmad Ibn Rustah (died in 903), Abu Al-Hasan AlMasudi (died in 956) and Abu Abdullah Muhammad Al-Idrisi (c. 1100-1165), mentioned the spherical shape of the earth in their books of traveling.

\subsection{Camera obscura}

In its simplest form the first camera in history, the camera obscura, is a shuttered room with a narrow aperture that admits light. The first recorded use of this optical system is in an optical treatise written by Al-Kindi. Decoding the nature of light was his concern in his attempts to setup a camera and therefore did not go much far in imaging systems. While the image forming ability of the camera was of little interest for Al-Kindi, this quality was of huge importance for Ibn Al-Haytham. The latter rapidly went beyond the scope of issue of the nature of light to investigate one of the most important behaviors of light, namely propagation. With determination, he defended the thesis of rectilinear propagation of light. His camera obscura was implemented to provide experimental evidence for this statement.

\subsection{Refraction}

In addition to his studies of reflection, he also studied refraction, a phenomenon in which light rays bend when traveling from one medium to another, such as from air to water. The effect causes an object to appear to be in a location other than where it actually is, making him the first scientist to test a property of refraction that seems so obvious today. He demonstrated that a ray of light arriving perpendicular to the air-water boundary was not bent at all and showed that this was true for light passing through not just two, but several media. Ibn AlHaytham's explanation of how a lens works enabled him to implement spectacles. He contended that magnification was due to refraction, the bending of light rays at the glass-to-air boundary and not, as thought before, to something inside the glass. He made the link between glass curvature and magnification. He is then credited with discovering that the magnifying effect takes place at the surface of the optical element rather than within it. 
It is quite surprising that Ibn Al-Haytham, who gave an outstanding explanation of the working of the optical system of the eye, who manufactured and used the first spectacles in history, who attempted to measure the thickness of the atmosphere, who worked on many others refractive components and systems, did not suggest a law for refraction. Our interpretation privileges two possibilities. First, he may actually have made this suggestion, but his writing was lost during wars and by negligence. Second, he may did not write it explicitly because it is well known before him and commonly used by Islamic scientists, like the fact that the earth is spherical (no one in the Islamic word debate on this issue).

\section{Experimental results}

An applet was designed to illustrate a very likely interpretation to Ibn Sahl's method to handle refraction [33]. Three rays are put into play: the incident, refraction and the extent rays. The extension ray (extension of the refraction ray into the incidence medium) is represented in dashed line. The incident and extension rays are considered as hypotenuses forming two rectangle triangles. The ratio extension to the incidence hypotenuse is constant and is a characteristic of the refractive medium (in the bottom in the applet). For simplicity, one can keep both hypotenuses constant as the case of the applet. This ratio is nothing else than the refraction index $n$ ' of the refractive medium if the incidence medium is air. As a consequence, the two extremities of the two hypotenuses move along a vertical line if one changes the incidence angle of the ray that meets a plane surface. We invite the reader to manipulate the applet [33], which presents our interpretation to Ibn Sahl's technique.

We propose a mechanical approach that enables illustrating the analogy between the refractive system and a mechanical equivalent [33]. The two rays (considered as hypotenuses previously) in the incidence medium 1 (top) are replaced by two sliding bars hanging on the application point, also moveable in the applet. Because the bars are solid and therefore their lengths are fixed, if we want to move one of the bars, the second one and also the vertical bar must move correspondingly. In summary, we need a mechanical system with three sliding bars. The special case, where the lengths of both hypotenuses are set to the values of the refraction indexes $n$ ( 1 if air) and $n^{\prime}$, is interesting. In this case, the method becomes similar to Young's method. Here also, we invite the reader to manipulate the applet developed for this purpose [34]. The lengths will be taken as the two radii of Young's scheme. Thus Young's method is covered by Ibn Sahl's method.

We also organized in Tunisia two photographic workshops [35,36] including conferences. Among others, the workshops offered us a valuable opportunity to open up to Ibn Al-Haytham's attempts and achievements. The camera obscura that he thoroughly studied was the theme of a training where more than twenty participants set up and used this basic camera. The training was designed for any photographer just starting out. The adopted training approach, based on active teaching and learning, allowed achieving interesting results in spite of the heterogeneity of the group of trainees. The training includes for major experimental lessons on how to set up and to use a camera obscura by means of only sheets of paper. The first two lessons were dedicated to the history of the camera obscura and on how to devise it in its most simple way. The next step was to initiate the group to implement their own camera obscura. It is worth noting that the group was heterogeneous. Moreover, the subject was very new for the trainees. Thus, the lectures were asked to popularize the experiments by avoiding forbidding mathematical formulas and simplifying complex concepts so that it can be easily understood by laypeople. The training approach has been chosen to incite trainees to be active and to efficiently improve their skills in optics and photography. Prior to experimentation, the trainees received theoretical instructions in a comprehensible way. They learn the photographing conditions to fulfill, and go through the process of photographing their favorite objects from start to finish on their own. Through interaction with the mentors, trainees were better able to understand the scientific way of thinking and doing things.

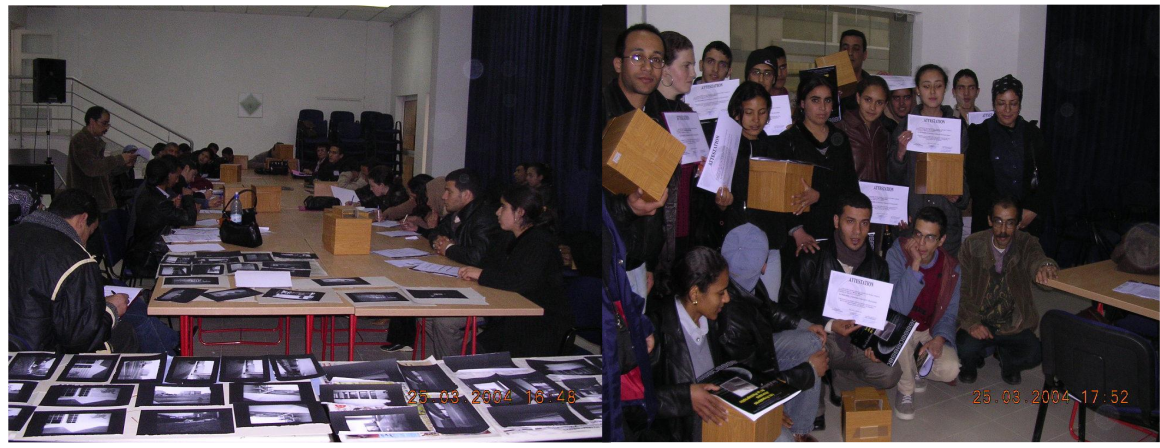

Figure 3: Photos of the workshop organized in Tunis in 2004. The boxes are the cameras oscura that the participants implemented by hand. 


\section{Conclusions}

Through simple examples, daunting formula and forbidding aspects may be popularized. Al-Haytham's attempts to understand challenging natural optical phenomena, like the rainbow, and to model complex and delicate systems, like the human eye, present start points to teach optics and especially geometrical optics. If Ibn AlHaytham with some primitive tools, not to say with no tools, could implement the first camera in the world, our students can easily rebuild this system in our relatively sophisticated laboratories. The idea is to come close to geometrical optics laws by observing the travel of the image forming rays through a hand made system.

As for the law of refraction, our interpretation to Ibn Sahl's technique offers an easy tool to manipulate the rays put into play by the phenomenon of refraction. By providing a material dimension, the mechanical approach further simplifies the refraction phenomenon. Because of the wave nature of light, optical rays do not exist actually and present a convenient fiction to illustrate that light travels in straight lines. In the same spirit, the mechanic approach may present a further fiction to illustrate refraction of light.

\section{References}

[1] A. Rey, "Les sciences orientales avant les grecs," Paris, 1942.

[2] C. Mugler, "Les origines de la science grecque chez Homère," Paris, 1964.

[3] Aristote, "Petits traités d'histoire naturelle," translation to French, Paris, 1953.

[4] T. Henri-Martine, "Hypothèse astronomique de Pythagore," Rome, 1872.

[5] R. Rashed, "Le discours de la lumière d'Ibn Al-Haytham," Traduction française critique Rev. d'hist. des Sci., T. XXI, 1968.

[6] A. Mieli, "La science arabe et son rôle dans l'évolution scientifique mondiale, par Aldo Mieli. Avec quelques additions de HenriPaul-Joseph Renaud, Max Meyerhof, Julius Ruska, E. J. Brill, Leiden 1938 et 1966.

[7] E. Wiedermann, "Zu Ibn Al-Haithams Optik," Archiv f. Geschichte der Naturwissen-schaft III, 1-53, 1910.

[8] J. Le Goff, "Les intellectuels au Moyen Age," Paris, 1957.

[9] A. C. Crombie, "Augustine to Galileo, the history of science," T. I, Heinemann Ltd, London, 1957.

[10] A. C. Crombie, "Robert Grossteste and the origins of the experimental science," Oxford, 1953.

[11] R. Descartes, "Oeuvres complètes de Descartes," T. IV, Paris, 1965.

[12] P. de Fermat, "Varie opera. math.," Tolasea, 1679.

[13] F. M. Grimaldi, "Physico-mathesis de Lumine, coloribus et irride," published just after his death, Bologna, 1665.

[14] I. Newton, "Principes mathématiques de la philosophie naturelle," (Translation to French 1756), Paris 1966.

[15] C. Huygens, "Traité d'optique," réédition, Paris, 1920.

[16] T. Young, "The bakerian lectures. On the theory of light and colours," Phil. trans., 1802.

[17] T. Young, "Outlines of experimentals and inquiries respecting sound and light," Phil. trans., 1800.

[18] A. Sommerfeld, "Optics, Lectures on theoretical Physics," Vol. IV, Academic Press Inc., New-York, 1954.

[19] D. C. Lindberg, "Medieval Islamic achievement in optics," OPN, 14, 30-35, 2003.

[20] D. C. Lindberg, "Theories of Vision from Al-Kindi to Kepler," Chicago: Univ. of Chicago Pr., 1976.

[21] S. Georges, "Introduction to the History of Science," Carnegie Institution of Washington, by the Williams and Wilkins Company, Baltimore.

[22] Hunain Ibn Ishaq wrote the first textbook of ophthalmology; see Meyerhof, 1928. See also; Fakhry, Majid, 1983 (1970), p 10, 12; Elgood, 1951, p 70, 75, 89, 100, 267-269; Hitti, 1956, 1956 (1937), p 313-364; Meyerhof, 1944, and O'Leary, 1957 (1949).

[23] R. Rashed, “A pioneer in anaclastics: Ibn Sahl on burning mirrors and lenses," Isis, 81, pp. 464-491, 1990.

[24] K. B. Wolf, "Geometric Optics on Phase Space," p. 9, Springer, 2004.

[25] R. Rashed, "Géométrie et dioptrique au Xe siècle: Ibn Sahl, Al-Quhi et Ibn Al-Haytham," Paris, Les Belles Lettres, 1993.

[26] A. Ad-Difaa, "Exact Sciences in Islamic Arab Civilization," $1^{\text {st }}$ Ed., Rissala Foundation, Beirut, 1981, Jan. 2007.

[27] Q. H. Tuquan, "The Arab scientific heritage in mathematics and astronomy," Beirut, Dar Al-Shuruq, 1963.

[28] R. Rashed, "Le modèle de la sphère transparente et l'explication de l'arc-en-ciel : Ibn Al-Haytham - Al-Farisi," Revue d'histoire des sciences, 22, 109-140, 1970.

[29] Biography in Dictionary of Scientific Biography, New York, 1970-1990.

[30] Arnold Sir Thomas, "Islamic Heritage," Translated in Arabic by Jarsis Fathallah, Beirut, Dar Talia, 1972.

[31] Ana Maroa Cetto, "Historia de la Optica," http://omega.ilce.edu.mx:3000/sites/ciencia/volumen 1/ciencia2/32/html/sec $8 . \mathrm{html}$

[32] A brief history of the microscope, http://www.hometrainingtools.com/articles/microbiology-cells-science-explorationsnewsletter.html

[33] H. Hamam, "Ibn Sahl's law of refraction: interpretation and analogy with a mechanical system," http://www.umoncton.ca/genie/electrique/Cours/Hamam/Optics/Refract/IbnSahl/IbnSahl.htm, Jan. 2007.

[34] H. Hamam, "Refraction of light," http://www.umoncton.ca/genie/electrique/Cours/Hamam/Optics/Refract/Refract.htm, May 2001.

[35] H-Eddine Bouali, Mourad Zghal, and Zohra Ben Lakhdar, "Popularisation of optical phenomena: establishing the first Ibn AlHaytham workshop on photography”, in Proc. ETOP’2005, Marseille, 24-27 Sept. 2005.

[36] Maria L. Calvo, Jay M. Enoch, V. Lakshminarayanan, "An extraordinary contribution of Ibn-Al-Hytham to Vision Science in the last millennium: An experience showing how vision mechanism is induced by external stimuli," in the $2^{\text {nd }}$ Ibn Al-Haytham Workshop on Photography, Douz, Tunisia, Dec. 2006. 